\title{
The Impact of STATCOM on Power Systems Protection Devices
}

\author{
N. A. Aly and A. M. Ewais \\ Department of Electrical Engineering, Faculty of Energy Engineering, Aswan University, \\ Aswan, Egypt
}

\begin{abstract}
This paper introduces the impact of installing FACTS devices on protection systems. STATCOM is used to indicate its impact on distance relay. To check the feasibility installing of STATCOM into power system for improving the distance relay performance, the zones are suggested (Z1, Z2 and Z3) and have been calculated in order to improve the performance of distance relay protection and to prevent circuit breaker disturbance tripping. The simulation results are carried out in MATLAB software. The results reveal that the apparent impedance doesn't change when the distance relay is tested without STATCOM device under different locations of faults. After installing STATCOM in transmission line, the apparent impedance doesn't change and it equals the actual impedance in spite of nsation modes of STATCOM.

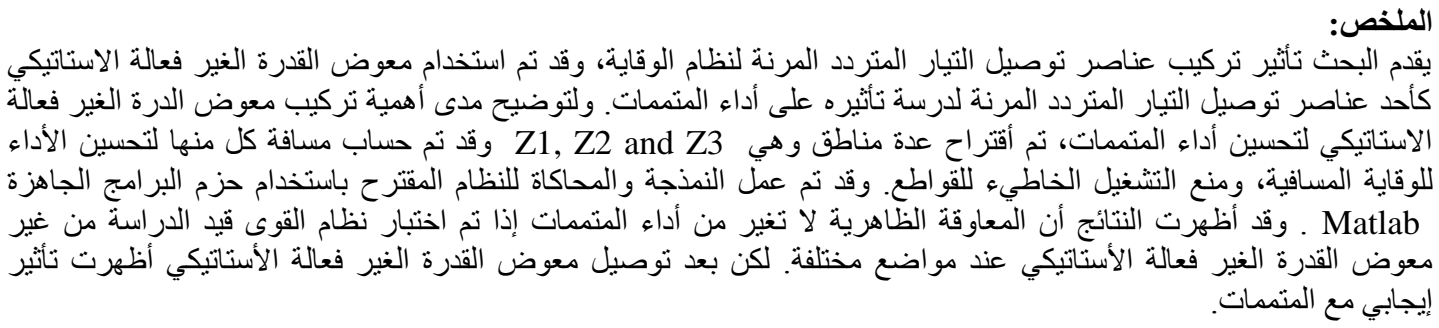

Keywords: Apparent Impedance, Circuit Breaker, Compensation modes, Distance relay, STATCOM.

\section{INTRODUCTION}

$\mathrm{C}$ Onsistent efforts to make power system more efficient and reliable have seen increased installing of FACTS devices in transmission systems [1]. Most of the FACTS devices are installed on existing transmission lines to improve the efficiency and reliability[1]. FACTS devices are classified into four types,(a) shunt (b) series (c) Combined series-series (d) Combined shunt-series[2]. FACTS devices are being actually applied for various applications, as follows[3]:

1. Increasing existing transmission lines capabilities.

2. Regulating voltage of transmission lines.

3. Improving transient and steady- stability.

4. Improving damping of power oscillation.

5. Correcting power factor.

6. Eliminating current harmonic.

Protection systems are applied in most countries of the world for the protection of high voltage transmission line due to their easy operating principle and ability to employ under most conditions [4]. Distance relays are used for the protection of transmission lines. They measure the impedance between the relay installing point and the point of fault location. The impedance of the transmission line per kilometer stays almost constant throughout the length of the transmission line. Consequently, the measured impedance of the relay is proportional to the distance to fault on the transmission line [5]. However, the implementation of FACTS devices in transmission systems insert new power system issues in the field of power system protection, in particular the line protection that must be studied and analyzed, such as, rapid changes in line impedance, power angle, load currents, and the transients because of the fault occurrence and the associated control action [6]. It is thus vitally necessary to study the impact of the FACTS devices on the protection devices scheme such as the impedance based distance protection relay [7].

\section{STUDIED SySTEM MODEL}

The test power system for the study is taken from [1] and is shown in Fig. 1. The distance relay is located at Station A, on Line I. The FACTS device is at the midpoint of the transmission line I.As a case study, simulation is modeled on a $230 \mathrm{KV}$ single circuit transmission lines, $300 \mathrm{~km}$ in length. 


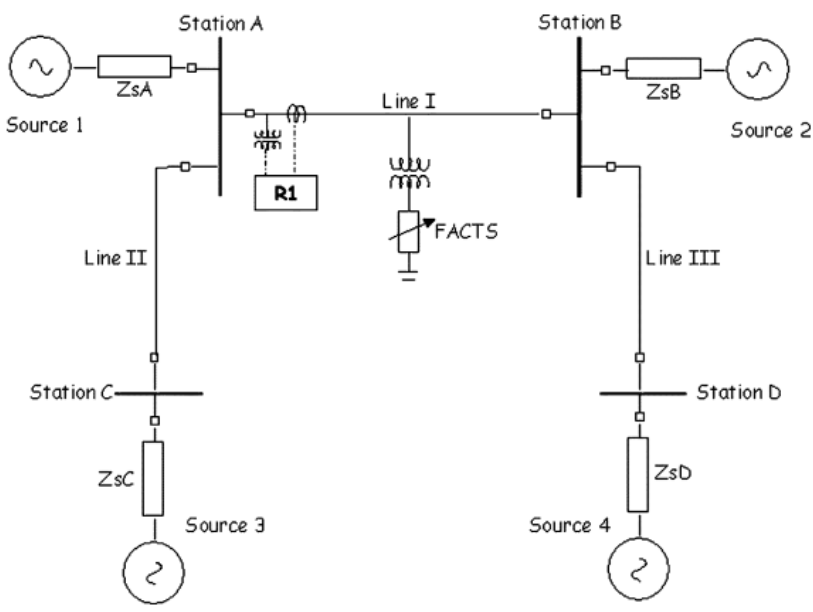

Fig 1 Single line diagram of the studied system

A. Three phase Transmission line Data

The three Phase Line block is used to perform a balanced three-phase transmission line .The transmission line data are assumed in Table 1 \{Transmission lines (I, II \& III) \}.

Table 1 Transmission Line Data

\begin{tabular}{|l|l|}
\hline Parameter & Value \\
\hline Line lengths & $300 \mathrm{~km}$ \\
\hline Positive seq. impedance & $0.51 \angle 85.92^{\circ} \Omega / \mathrm{k} \mathrm{m}$ \\
\hline Zero seq. impedance & $1.385 \angle 74.68^{\circ} \Omega / \mathrm{k} \mathrm{m}$ \\
\hline
\end{tabular}

B. Three-Phase Source Data

The Three-Phase Source block accomplishes a balanced three-phase voltage source with internal R-L impedance. The three voltage sources are connected in $\mathrm{Y}$ with a grounded neutral. The source data are assumed in Table 4.2 \{Equivalent sources $(1,2,3 \& 4)\}$ :

Table 2 Three-Phase Source Data

\begin{tabular}{|l|l|}
\hline Parameter & Value \\
\hline Power rating & $100 \mathrm{MVA}$ \\
\hline System voltage & $230 \mathrm{kV}$ \\
\hline System frequency & $60 \mathrm{~Hz}$ \\
\hline Positive seq. impedance & $25.9 \angle 80.0^{\circ} \Omega$ \\
\hline Zero seq. impedance & $25.9 \angle 80.0^{\circ} \Omega$ \\
\hline
\end{tabular}

\section{STATCOM}

The test power system consists of STATCOM installed at the mid-point of the transmission line connecting between Source- 1 and Source- 2 .The STATCOM compensates for the reactive power and its value changes with the power transfer between the sending and receiving ends to keep constant voltage at the midpoint.
Table 3 STATCOM Data

\begin{tabular}{|l|l|}
\hline Parameter & value \\
\hline Interfacing transformer & 3 winding (Y/y/d) \\
\hline Transformer ratio & $230 / 11 \mathrm{kV}$ \\
\hline Transformer rating & $100 \mathrm{MVA}$ \\
\hline Transformer impedance & $0.1 \mathrm{pu}$ \\
\hline $\begin{array}{l}\text { STATCOM rating(inductive \& } \\
\text { capacitive) }\end{array}$ & $100 \mathrm{MVAR}$ \\
\hline
\end{tabular}

D. Distance Relay

Distance relaying is called step distance protection. Several zones are employed to protect a transmission line. Distance relays have Zone 1, Zone 2, and Zone 3.

Distance Step Zone 1 is usually set to a reach in the range of 80 to 90 percent of the positive-sequence line impedance while the remaining $20 \%$ is to account for the accuracies of the current and voltage transformers feeding the distance relay.

Distance Step Zone 2 is usually put to a reach in the range of 120 to 150 percent of the positive-sequence line impedance. Others base the Zone 2 reach on the full line impedance plus a percentage of the neighboring line impedance as an additional criterion.

Distance Step Zone 3 is used for backup protection in the event of a failure at the remote bus. Reaches of 200 percent or more of line impedance are common with Zone 3[8].

Table 4: Three Zones Setting Impedance

\begin{tabular}{|l|l|l|}
\hline $\begin{array}{l}\text { Zones of } \\
\text { protection }\end{array}$ & Zone converge & length \\
\hline Zone-1 & $80 \%$ of line-1 & $80 \mathrm{~km}$ \\
\hline Zone-2 & $100 \%$ of line-1+20\% of lin-2 & $120 \mathrm{~km}$ \\
\hline Zone-3 & $\begin{array}{l}100 \% \text { of line-1+100\% of lin- } \\
2+20 \% \text { of lin-3 }\end{array}$ & $220 \mathrm{~km}$ \\
\hline
\end{tabular}

\section{Digital SimUlation RESUlts}

To study the impact of STATCOM on performance of distance relay, we used 48-puls STATCOM was designed by MATLAB/SIMULINK environment and it has many applications like regulate voltage by setting the desired reference voltage, fix the reactive power, and fix the reactive current. The STATCOM installed at $100 \mathrm{~km}$ of transmission line.

A. Single Line to Ground Fault

Single line to ground fault is the most common fault in transmission lines ,such as AG, BG or, CG. The impedance path for any single line to ground fault is the 
same. That, AG fault will be presented as an example in this paper. When a fault occurs before FACTS location ( such as a fault at $50 \mathrm{~km}$ ), the apparent impedance seen by distance relay is equal to the actual impedance in any case of compensation mode of FACTS devices as shown in figure (2) and figure (3). but in case of a fault at $200 \mathrm{~km}$ with capacitive compensation, the fault occurs in zone 3 but the impedance path shows the fault is out of protected area of zone $3(220 \mathrm{~km})$ as shown in figures (2) and (3) .

We use Figure( 4) to show the difference measured impedance values as seen by distance relay with and without STATCOM for both cases capacitance and inductive compensation. We take the single line to ground fault (for phase A) every $20 \mathrm{~km}$.

The analysis of result of single line to ground fault:

1. The STATCOM impact on impedance of distance relay.

2. The measuring impedance of distance relay when the fault before the STATCOM doesn't change but in case of the fault after the STATCOM it will be greater than the actual impedance in case of capacitive compensation and will less than the actual impedance in case of inductive compensation.

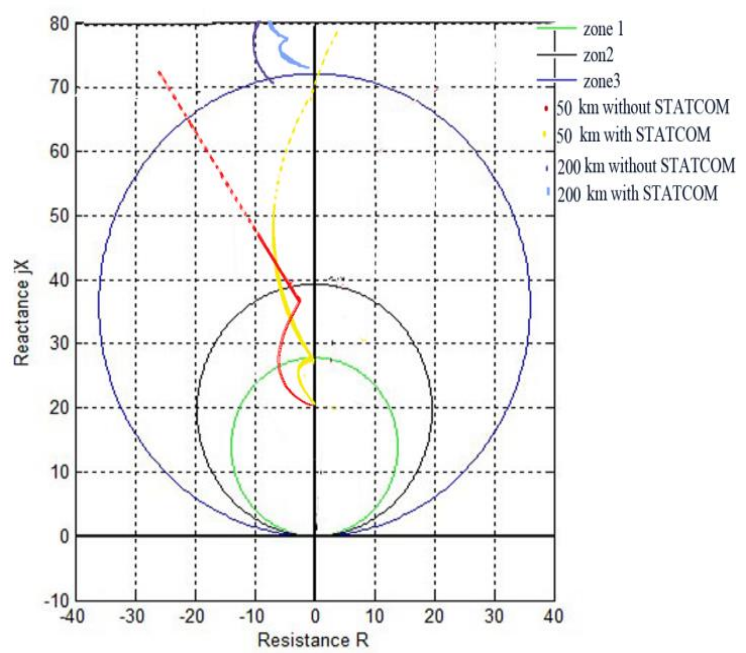

Fig . 2 Impedance path for phase A to ground fault withnut and with ST $\triangle T C \cap M$ inctalled at $10 \cap \mathrm{km}$

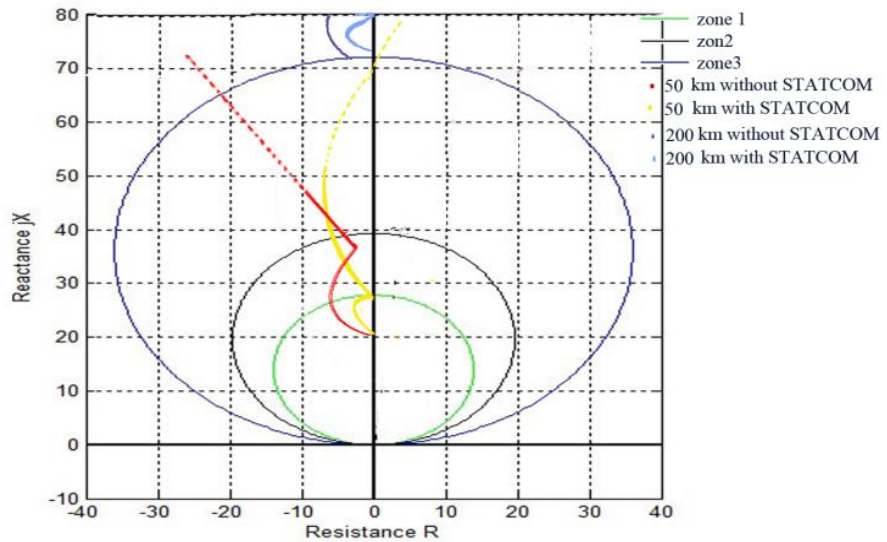

Fig . 3 Impedance path for phase A to ground fault without and with STATCOM installed at $100 \mathrm{~km}$ (STATCOM in

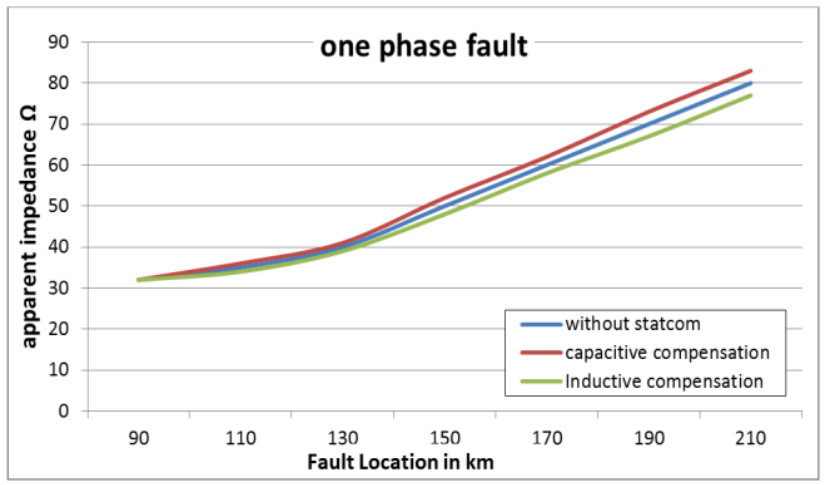

Fig. 4 Apparent impedance measurement for different fault locations and a variety of STATCOM operation

B. Double Line and Double Line to Ground Fault

The Double Line and double line to ground fault is similar to single line to ground fault, we applied the fault before and after STATCOM to see the impact the STATCOM on distance relay .AB, ABG, BC, BCG, AC ,and ACG fault types are simulated and results also in similar impedance path. 


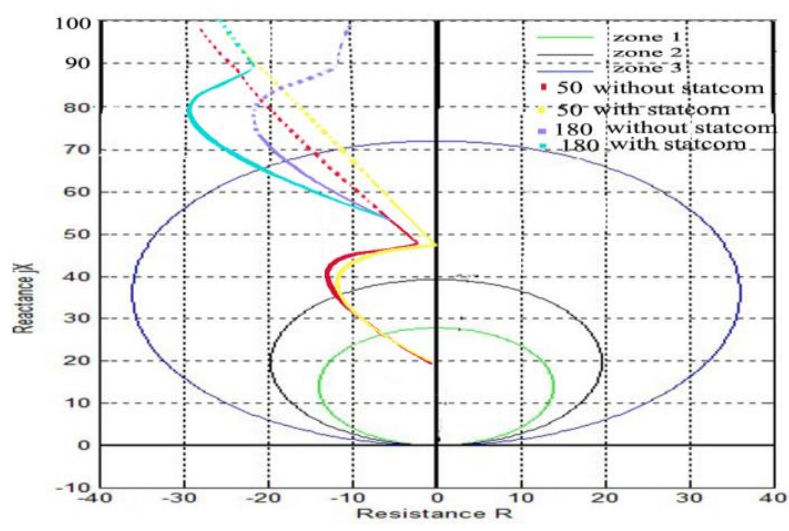

Fig. 5 Impedance path for double line fault without and with STATCOM installed at $100 \mathrm{~km}($ STATCOM in

The impedance path for double line and double line to ground fault is similar to the actual impedance when fault occurs before STATCOM as shown in figures (5) and (6), but in case of the fault after the STATCOM there is difference between the actual impedance of transmission line and the impedance of compensation transmission line. we notice that in figure (7) is similar to figure(4).The apparent impedance in case of without STATCOM is different about the apparent impedance when there is STATCOM ,but when there is capacitive compensation is larger than the actual impedance and when there is inductive compensation, it is less than actual impedance

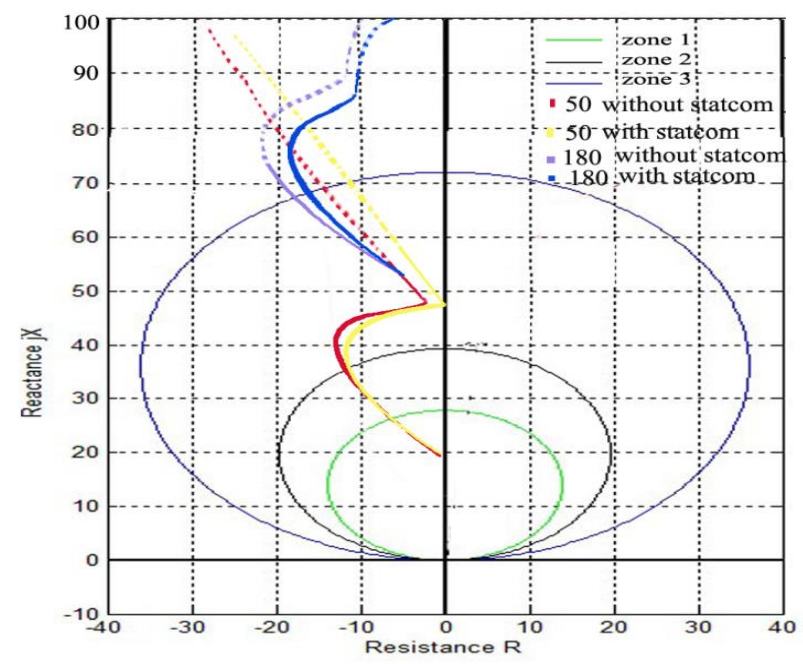

Fig .6 Impedance path for double line fault without and with STATCOM installed at $100 \mathrm{~km}$ (STATCOM in

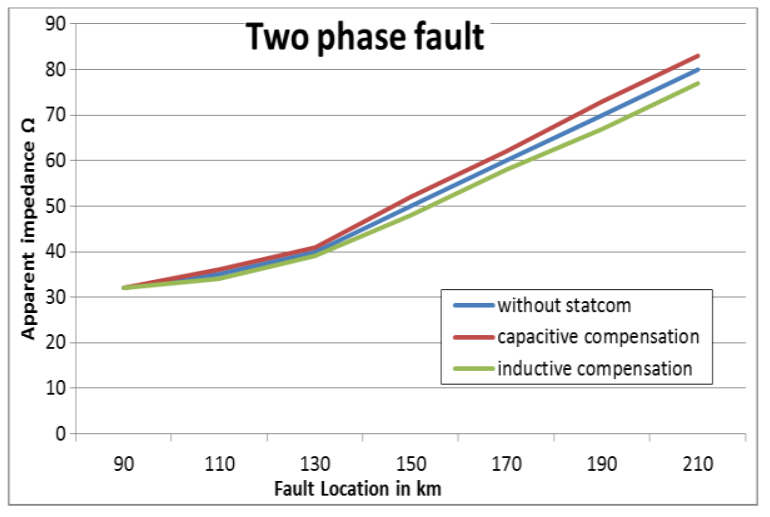

Fig. 7 Apparent impedance measurement for different fault locations and a variety of STATCOM

C. Three Line Fault and Three Line Fault with Ground The same system has been tested for the three-phase faults. The fault is applied before and after STATCOM to see the impact the STATCOM on distance relay . $\mathrm{ABC}$, and $\mathrm{ABCG}$ fault types are simulated and results also in similar impedance path. We note from figures (8), ( 9) , and (10) there is no effect of STATCOM on the measured impedance when the fault before the STATCOM, but when the fault occurs after the STATCOM the effect of STATCOM is like to the other cases of faults. But in three line and three line to ground fault in case of inductive compensation the apparent impedance is larger than the actual impedance and in case of capacitive compensation is less than the actual impedance.

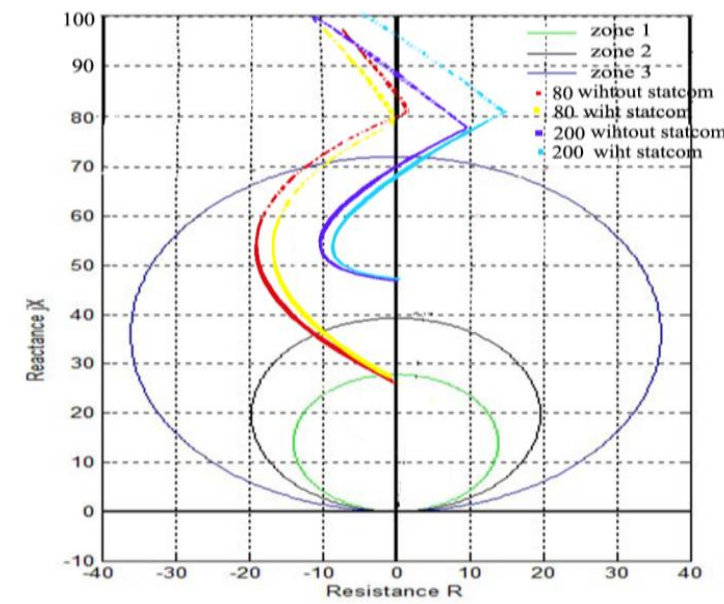

Fig . 8 Impedance path for three line fault without and with STATCOM installed at $100 \mathrm{~km}$ 


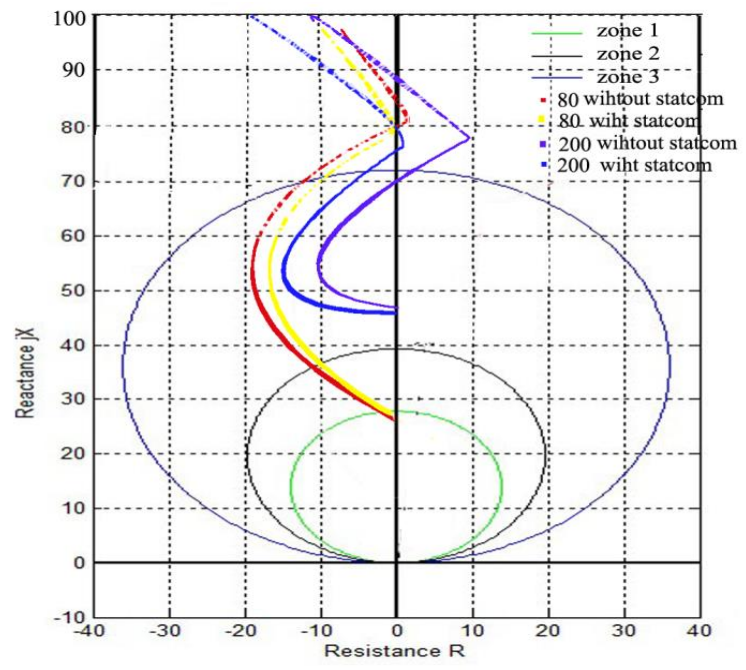

Fig . 9 Impedance path for three line fault without and with STATCOM installed at $100 \mathrm{~km}$ (STATCOM in

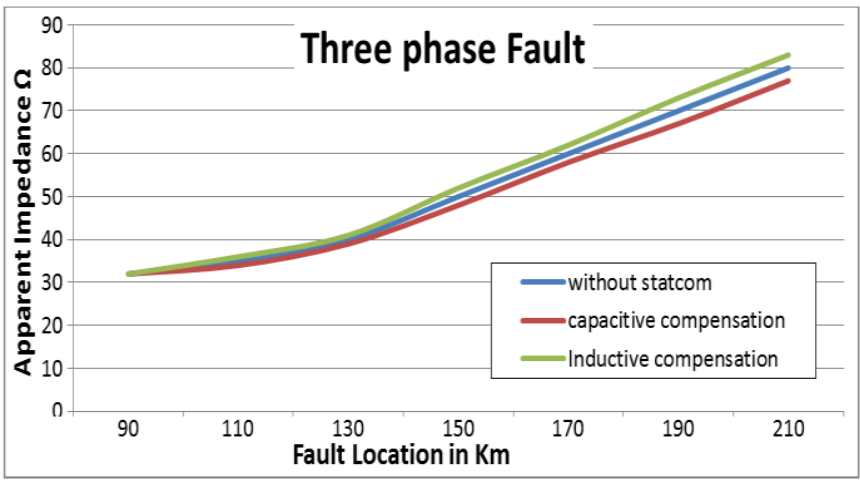

Fig. 10 Apparent impedance measurement for different fault locations and a variety of STATCOM operation modes for

\section{CONCLUSION}

The apparent impedance doesn't change when the distance relay is tested without STATCOM device under different location and faults. After installing STATCOM in transmission line, during the fault occurring between FACTS (STATCOM) and distance relay, the apparent impedance doesn't change and it equals the actual impedance in spite of compensation modes of STATCOM. When the fault occurs after the location of STATCOM, there is a change in the apparent impedance. In case of capacitive compensation, the apparent impedance is more than the actual impedance. However, in the case of inductive compensation, the apparent impedance is less than the actual impedance. In case of three lines to ground fault, the measuring impedance in case of inductive compensation is more than the actual impedance, while in case of capacitive compensation it is less than the actual impedance. In all fault case studies, there is an error in the measured impedance accomplished by distance relay as it increases during changing the location of the fault from STATCOM device's location to the end of the relay reach-line.

\section{REFERENCES}

[1] Sidhu, Tarlochan Singh, et al. "Performance of distance relays on shunt-FACTS compensated transmission lines." IEEE Transactions on Power delivery 20.3 (2005): 1837-1845.

[2] Hingorani, Narain G., Laszlo Gyugyi, and Mohamed El-Hawary. Understanding FACTS: concepts and technology of flexible AC transmission systems. Vol. 1. New York: IEEE press, 2000

[3] Mathur, R. Mohan, and Rajiv K. Varma. Thyristorbased FACTS controllers for electrical transmission systems. John Wiley \& Sons, 2002.

[4] Zhang, Wen-Hao, et al. "Considerations on distance relay setting for transmission line with STATCOM." Power and Energy Society General Meeting, 2010 IEEE. IEEE, 2010.

[5] Sham, M. V., and K. Panduranga Vittal. "Simulation studies on the distance relay performance in the presence of STATCOM." Journal of Electrical Engineering (JEE) 11.3 (2011): 11-18.

[6] Albasri, Fadhel A., Tarlochan Singh Sidhu, and Rajiv K. Varma. "Performance comparison of distance protection schemes for shunt-FACTS compensated transmission lines." IEEE Transactions on Power Delivery 22.4 (2007): 21162125.

[7] Alapati, Sriteja, and B. Durga prasad "Effect of statcom on distance relay performance in a transmission line." International Journal of Computer and Electrical Engineering 4.4 (2012): 489.

[8] Thompson, Michael J., and Daniel L. Heidfeld. "Transmission line setting calculations-beyond the cookbook." Protective Relay Engineers, 2015 68th Annual Conference for.IEEE, 2015. 